\title{
Effect of treatment modality on the long-term survival of patients with early glottic squamous cancer: a retrospective cohort study based on the SEER database
}

\author{
Wen-Lun Wang", Hong-Wei Zheng", Li-Hong Zhang, Li-Sheng Yu \\ Department of Otorhinolaryngology-Head and Neck Surgery, Peking University People's Hospital, Beijing, China \\ Contributions: (I) Conception and design: LS Yu, LH Zhang; (II) Administrative support: LS Yu, LH Zhang; (III) Provision of study materials or \\ patients: WL Wang, HW Zheng; (IV) Collection and assembly of data: WL Wang, HW Zheng; (V) Data analysis and interpretation: WL Wang; (VI) \\ Manuscript writing: All authors; (VII) Final approval of manuscript: All authors. \\ \#These authors contributed equally to this work. \\ Correspondence to: Li-Hong Zhang, MD; Li-Sheng Yu, MD. Department of Otorhinolaryngology-Head and Neck Surgery, Peking University \\ People’s Hospital, Beijing, China. Email: lihongzhangent@163.com; lishengyuent@163.com.
}

\begin{abstract}
Background: The optimal treatment strategy for patients with early glottic (T1-2N0M0) squamous cancer remains unclear.

Methods: A retrospective population-based analysis was performed using the Surveillance, Epidemiology, and End Results (SEER) database. Propensity score matching (PSM) was used to balance treatment arms, and Cox regression analysis was used to determine prognostic factors for survival. Kaplan-Meier analysis, log-rank tests, and competing risk analysis were used to compare survival outcomes between treatment modalities (surgery vs. radiotherapy).

Results: Among the 3,994 eligible patients in this study, surgery was associated with improved cancerspecific survival (CSS) and overall survival (OS) compared with radiotherapy (log-rank test, $\mathrm{P}<0.05$ ). This survival trend favoring surgery was consistent in the T1a, well/moderately differentiated grade, male, and all age subgroups. However, after the baseline characteristics were balanced with PSM, the survival outcomes (CSS and OS) did not differ significantly between the surgery and radiotherapy groups. Interestingly, surgery was associated with a $39 \%$ reduced risk of cancer-related death compared with radiotherapy in patients aged $\geq 70$ years (hazard ratio $0.61 ; 95 \% \mathrm{CI}: 0.43-0.87 ; \mathrm{P}=0.006$ ). However, this survival trend favoring surgery was not observed in younger patients (age $<70$ years), $T$ stage subgroups, male or female subgroups, or in any of the pathological grade subgroups.

Conclusions: In patients with early glottic squamous cell carcinoma undergoing surgery or radiotherapy, there is no sufficient evidence favoring one method over another in terms of survival. However, surgery is recommended in patients aged $\geq 70$ years because, in this group, it was associated with improved survival outcomes compared with radiotherapy.
\end{abstract}

Keywords: Glottic cancer; propensity score matching (PSM) study; Surveillance, Epidemiology, and End Results registry (SEER registry); radiotherapy; surgery

Submitted Oct 04, 2021. Accepted for publication Jan 14, 2022.

doi: $10.21037 / \mathrm{atm}-21-5288$

View this article at: https://dx.doi.org/10.21037/atm-21-5288

\section{Introduction}

Laryngeal cancer is the second most common malignancy in the head and neck (1). It is estimated that, in 2021, there will be approximately 12,620 new cases of laryngeal cancer and 3,770 deaths in the United States (2). Histologically, the vast majority of laryngeal cancers are squamous cell 
carcinoma (SCC). Glottic cancer is the most common type of laryngeal cancer, accounting for approximately two-thirds of all laryngeal cancers (3). Because glottic cancer disturbs vocal function, these lesions are often diagnosed at an early stage. Survival for early glottic (T1T2NOM0) carcinoma is high, with a 5 -year survival rate $>90 \%$ (4).

The strategy for early glottic cancer is single-modality treatment (radiotherapy or surgery), highlighting the importance of larynx preservation and voice quality (5). Over the past two decades, transoral laser microsurgery (TLM) has supplanted open surgery as the mainstay surgical approach (6). Compared with open surgery, TLM has the advantages of being minimally invasive, lower cost, and associated with faster rehabilitation. If relapse occurs, salvage surgery or radiotherapy can be performed after the initial surgery. Typically, early stage glottic lesions are treated with a radiation dose of 50-70 Gy with 2-2.5 Gy/fraction. There is evidence that patients treated with radiotherapy have better voice quality than those treated with surgery (7). In recent years, intensitymodulated radiation therapy has become the most popular radiotherapy modality, with demonstrated superiority in reducing treatment-related toxicities.

Overall, given the lack of prospective randomized controlled trials, there is no sufficient evidence supporting one treatment method over another regarding oncological outcomes (8). Early glottic cancer is a heterogeneous disease. Tumors may exhibit different characteristics that make them appropriate for specific treatment methods. In addition, for a cancer with a high survival rate, a large sample size with long-term follow-up is necessary when treatment effects are evaluated. Consequently, the aims of the present study were to evaluate survival outcomes following surgery or radiotherapy in early glottic cancer and to identify patient-related characteristics associated with treatment effect by analyzing the Surveillance, Epidemiology, and End Results (SEER) database. We present the following article in accordance with the STROBE reporting checklist (available at https://atm. amegroups.com/article/view/10.21037/atm-21-5288/rc).

\section{Methods}

\section{Data collection}

Data (2005-15) from the SEER program (IncidenceSEER 18 Regs Research Data + Hurricane Katrina Impacted Louisiana Cases, Nov 2015 Sub) was extracted for T1-2N0M0 glottic SCC. Briefly, data of patients with primary site labeled "C32.0-Glottis", behavior code "ICD-0-3=malignant", and TNM sixth edition "(2004+) $=\mathrm{T} 1-2 \mathrm{~N} 0 \mathrm{M} 0$ " were included in the analysis. Patients were excluded if they met any of the following criteria: (I) they did not have SCC; (II) there was no pathological confirmation; (III) this was not the patients first primary cancer; (IV) if radiotherapy administered, it was no not beam radiation; $(\mathrm{V})$ patients were treated with both radiotherapy and surgery; and/or (VI) critical information, such as treatment modalities, TNM classification, or pathological grade, was missing. In this study, surgery included local tumor resection (with or without laser assistance), hemilaryngectomy, and total laryngectomy (with or without neck dissection). Radiotherapy included only external beam radiation. The present study was a cohort study, and patients were divided into 2 groups based on whether they received radiotherapy or surgery.

Demographic and clinical characteristics, including age (categorical variable; $\geq 70$ and $<70$ years), sex, race, marital status, diagnosis time (categorical variable), $\mathrm{T}$ stage, and pathological grade were collected from the database. "SEER disease-specific death classification" and "SEER other-cause death classification" codes were used to evaluate cancerspecific survival (CSS) and other cause-specific survival. Patients who were lost to follow-up or were still alive at the last follow-up were defined as censored.

This study was conducted in accordance with the Declaration of Helsinki (as revised in 2013). Because SEER does not contain information that could identify patients, this study was deemed to be exempt from review by the institutional ethics committee of Peking University People's Hospital.

\section{Statistical analysis}

Because the patients were not randomly assigned in this retrospective study, the baseline covariates of the 2 groups might have been unbalanced which could have affected the evaluation of treatment results. Thus, propensity score matching (PSM) was used to minimize differences in baseline characteristics between the 2 groups with the "Nonrandom" $\mathrm{R}$ package. The propensity score (PS) of each patient was calculated with a logistic regression model that included the following variables: age, sex, race, insurance status, pathological grade, $\mathrm{T}$ stage, marital status, and diagnosis time. Each patient in the surgery group was matched 1:1 with a corresponding patient in the radiotherapy group using a nearest-neighbor PS matching algorithm with a caliper 
Table 1 Demographic and clinical characteristics of the overall study cohort

\begin{tabular}{|c|c|}
\hline Characteristics & No. of patients, $n(\%) n=3,994$ \\
\hline \multicolumn{2}{|l|}{ Gender } \\
\hline Male & $3,573(89.5)$ \\
\hline Female & $421(10.5)$ \\
\hline \multicolumn{2}{|l|}{ Age (years) } \\
\hline 49 and below & $385(9.6)$ \\
\hline $50-59$ & $907(22.7)$ \\
\hline $60-69$ & $1,294(32.4)$ \\
\hline $70-79$ & $987(24.7)$ \\
\hline 80 and over & $421(10.5)$ \\
\hline \multicolumn{2}{|l|}{ Race } \\
\hline White & $3,363(84.2)$ \\
\hline Black & $479(12.0)$ \\
\hline other & $152(3.8)$ \\
\hline \multicolumn{2}{|l|}{ Marry status } \\
\hline Married & $2,622(65.6)$ \\
\hline Single & $1,372(34.4)$ \\
\hline \multicolumn{2}{|l|}{ Insurance status } \\
\hline Uninsured & $22(0.6)$ \\
\hline Insured & $718(18.0)$ \\
\hline unknown & $3,154(81.5)$ \\
\hline \multicolumn{2}{|l|}{ Pathological Grade } \\
\hline Well differentiated & $1,200(30.0)$ \\
\hline Moderately differentiated & $2,328(58.3)$ \\
\hline Poorly differentiated & $448(11.2)$ \\
\hline undifferentiated & $18(0.5)$ \\
\hline \multicolumn{2}{|l|}{ T stage } \\
\hline $\mathrm{T} 1 \mathrm{a}$ & $2,026(50.7)$ \\
\hline $\mathrm{T} 1 \mathrm{~b}$ & $382(9.6)$ \\
\hline T1nos & $579(14.5)$ \\
\hline $\mathrm{T} 2$ & $1,007(25.2)$ \\
\hline \multicolumn{2}{|l|}{ Diagnosis time (years) } \\
\hline 2005-2009 & $1,031(25.8)$ \\
\hline 2010-2015 & $2,963(74.2)$ \\
\hline \multicolumn{2}{|l|}{ Treatment modality } \\
\hline Surgery & $898(22.5)$ \\
\hline Radiotherapy & $3,096(77.5)$ \\
\hline
\end{tabular}

size of $x=0.05$. A standardized difference value of $<10 \%$ after matching was considered balanced.

Chi-square tests were used to compare baseline characteristics between the treatment groups before and after PSM. Kaplan-Meier analysis and log-rank tests were used to compare survival patterns between groups. According to a previous report (9), competing risk analysis was performed with other cause-specific death as a competing risk. Variables that were significant in univariate analysis at a level of $\mathrm{P}<0.05$ were included in the multivariate analysis. Variables that are significant in clinical practice, such as diagnosis time, were also included (10). Cox regression analysis was performed to calculate adjusted hazard ratios (aHRs) of CSS and overall survival (OS) before and after PSM. A 2-sided $\mathrm{P}$ value $<0.05$ was considered statistically significant. All analyses were performed using SPSS version 22.0 (IBM Corp., Armonk, NY, USA) and R version 3.5.2 (The R Foundation for Statistical Computing, Vienna, Austria).

\section{Results}

\section{Patient characteristics and survival analyses before PSM}

In all, data for 3,994 patients satisfying the inclusion criteria were analyzed. The mean $( \pm \mathrm{SD})$ patient age was $65 \pm 11.4$ years, and the median follow-up time was 86 months (interquartile range 51-127 months). Most patients were male $(89.5 \%)$, married $(65.6 \%)$, and White $(84.2 \%)$. Just over half the patients were diagnosed with T1a disease $(50.7 \%) ; 22.5 \%(\mathrm{n}=898)$ underwent surgery and $77.5 \%(n=3,096)$ were treated with radiotherapy. The 5 -year OS rate was $71.3 \%$ (95\% CI: 69.9-72.7\%), and the 5-year CSS rate was $84.8 \%$ (95\% CI: 83.6-86\%). Detailed information is provided in Table 1. There were more T2 patients in the radiotherapy than surgery group. KaplanMeier analysis (Figure 1) revealed that the 5-year CSS was significantly higher for patients in the surgery than in the radiotherapy group $(89.5 \%, 95 \%$ CI: $87.3-91.6 \%$ vs. $83.4 \%, 95 \%$ CI: $82.0-84.7 \%$; log-rank test $\mathrm{P}<0.001)$ as was 5 -year OS (75.9\%, 95\% CI: 73.2-78.6\% vs. 70\%, $95 \%$ CI: 68.4-71.5\%; log-rank test $\mathrm{P}=0.001)$. After stratification by $\mathrm{T}$ stage, age, pathological grade, and sex, surgery remained significantly associated with prolonged CSS in the T1a, well/moderately differentiated grade, male sex, and all age subgroups (Figure S1).

We also performed univariate survival analysis (Table S1) and further multivariate regression analysis in the overall cohort (Table S2). Age, sex, race, marital status, T stage, and 

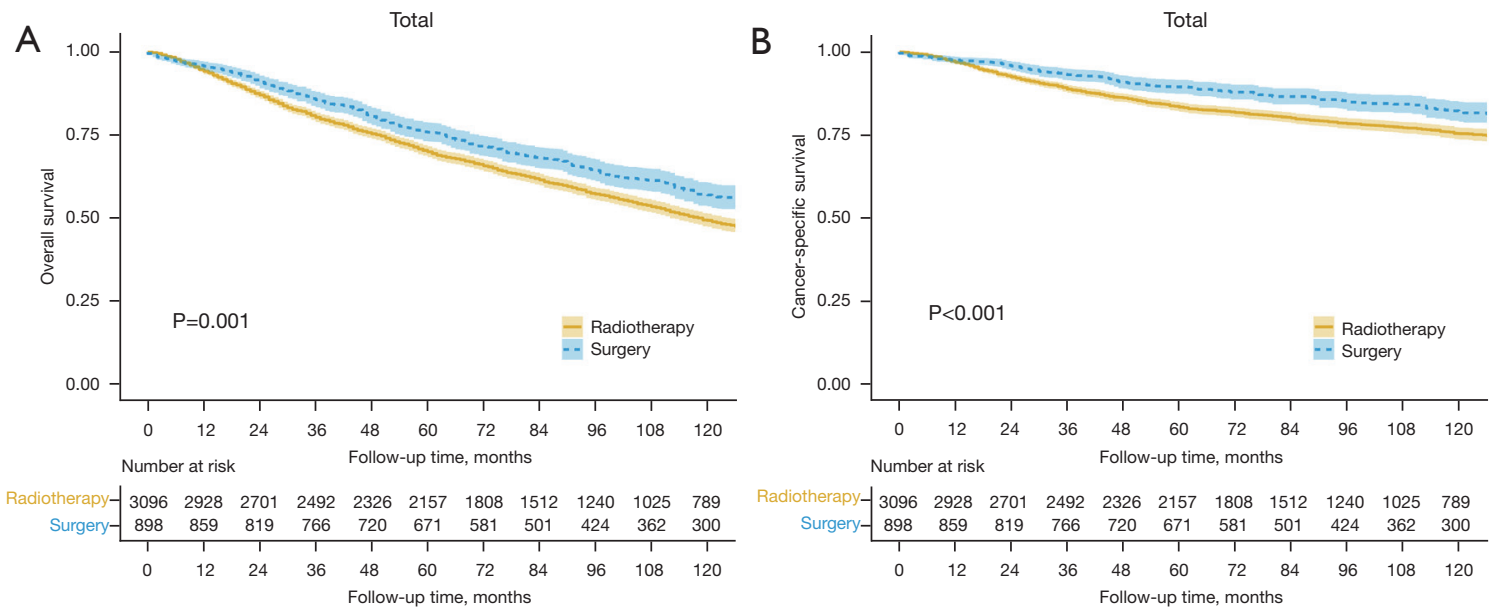

Figure 1 Survival analyses for patients with early glottic cancer before propensity score matching. (A) Overall survival and (B) cancerspecific survival for patients in the surgery and radiotherapy groups. Dashed and solid lines indicate survival rates, with shaded areas indicating $95 \%$ CIs.

treatment were identified as independent prognostic factors for OS in multivariate analysis. Patients undergoing surgery had a $13 \%$ reduced risk of death than did those receiving radiotherapy (aHR 0.87, 95\% CI: 0.78-0.97; P=0.015). In addition, age, race, marital status, $\mathrm{T}$ stage, and treatment remained independent prognostic factors for CSS. Patients undergoing surgery had a $22 \%$ decreased risk of cancerspecific death than did those receiving radiotherapy (aHR 0.78, 95\% CI: 0.65-0.94; $\mathrm{P}=0.009$ ).

More survival analyses can be found in the supplementary.

\section{Propensity score matching}

Before further analysis, patients treated with surgery were matched with patients treated with radiotherapy based on their PS. As can be seen in Table 2, there were significant differences in demographic variables and clinical characteristics between the 2 treatment cohorts. The chisquare test indicated that patients treated with surgery had a better $\mathrm{T}$ stage $(\mathrm{P}<0.001)$, were more likely to be diagnosed between 2005 and $2009(\mathrm{P}<0.001)$, and were less likely to be Black $(\mathrm{P}=0.004)$. After matching, there was no statistically significant difference in covariates between the 2 groups $(\mathrm{P}>0.05)$. The absolute values of standardized differences in baseline variables were all $<10 \%$ (Figure 2), suggesting that the variables between 2 comparator groups were well balanced after matching.

\section{Patient characteristics and survival analyses after PSM}

PSM generated 898 matched pairs of patients with early glottic cancer in the surgery and radiotherapy groups (Table 2). Kaplan-Meier analysis was performed to investigate the survival curves of the overall cohort. There was no significant difference in the 5 -year OS between the surgery and radiotherapy groups $(75.9 \%, 95 \% \mathrm{CI}$ : 73.1-78.6\% vs. $71.9 \%$, $95 \%$ CI: $68.5-74.4 \%$; log-rank test $\mathrm{P}=0.21$; Figure $3 A$ ). In addition, there was no significant difference in the 5 -year CSS between the surgery $(89.5 \%$, 95\% CI: $87.4-91.6 \%)$ and radiotherapy groups (85.3\%, 95\% CI: 82.9-87.6\%; log-rank test $\mathrm{P}=0.13$; Figure $3 B$ ).

Univariate analysis was conducted to preliminarily screen prognostic factors for survival (Table S3). And then Cox regression analysis after PSM demonstrated that age, marital status, and $\mathrm{T}$ stage were independent risk predictors for OS and CSS (Table 3). However, treatment modality was not identified as an independent prognostic factor for OS (aHR 0.89, 95\% CI: 0.78-1.02; $\mathrm{P}=0.103$ ) or CSS (aHR 0.80, 95\% CI: 0.64-1.00; $\mathrm{P}=0.055)$. Competing risk analysis revealed that both cancer-specific mortality and other causes of mortality were comparable between the surgery and radiotherapy groups (Figure 3C).

To explore whether the therapeutic effects of the 2 treatment modalities are consistent in patients with early glottic laryngeal cancer but with different clinical features, subgroup analyses were conducted (Figure 4 and Figure S2). 
Table 2 Patient characteristics stratified by treatment modalities before and after propensity score matching

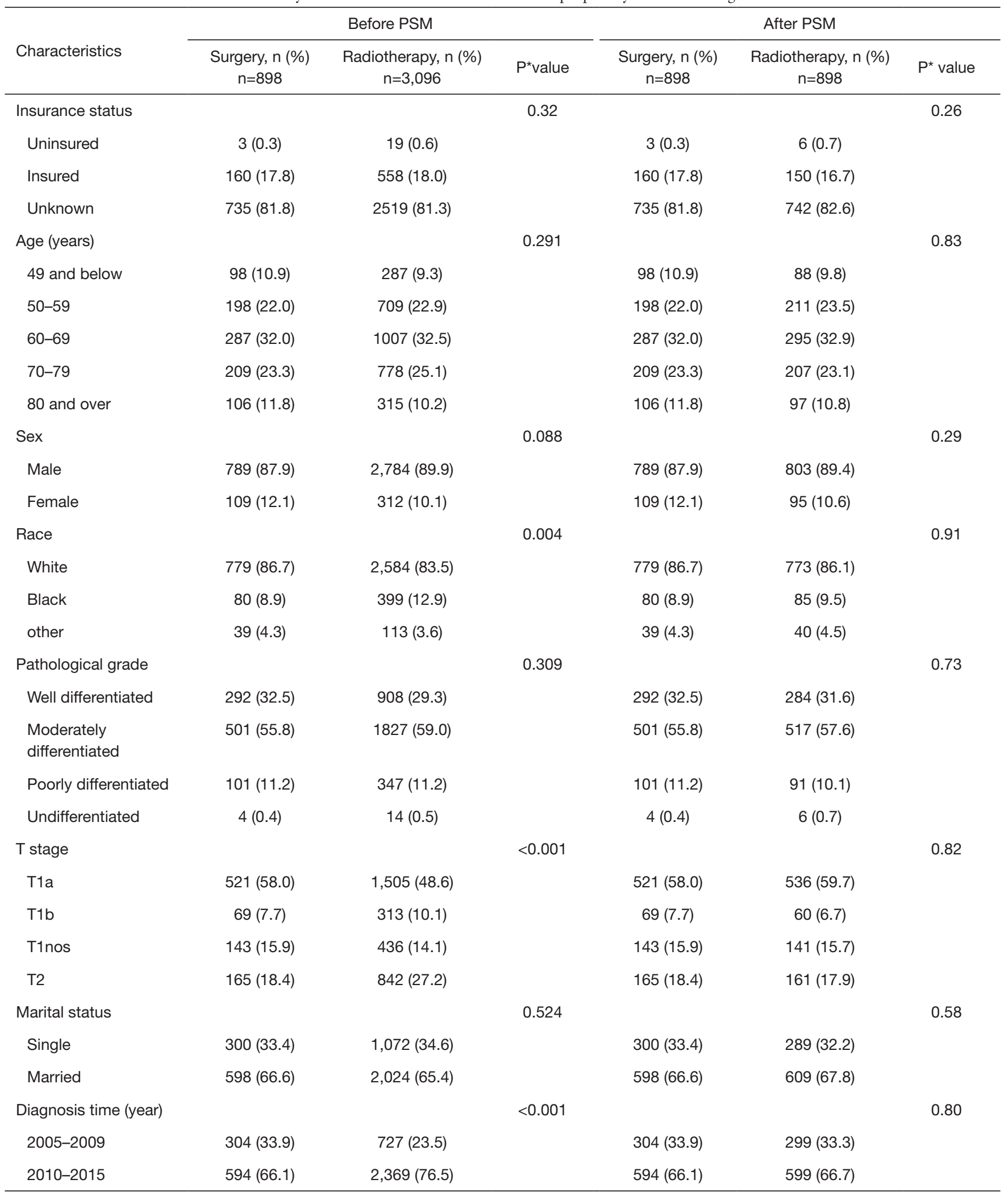

*, Chi-square test. T1nos, T1 not specific; PSM, propensity score matching. 


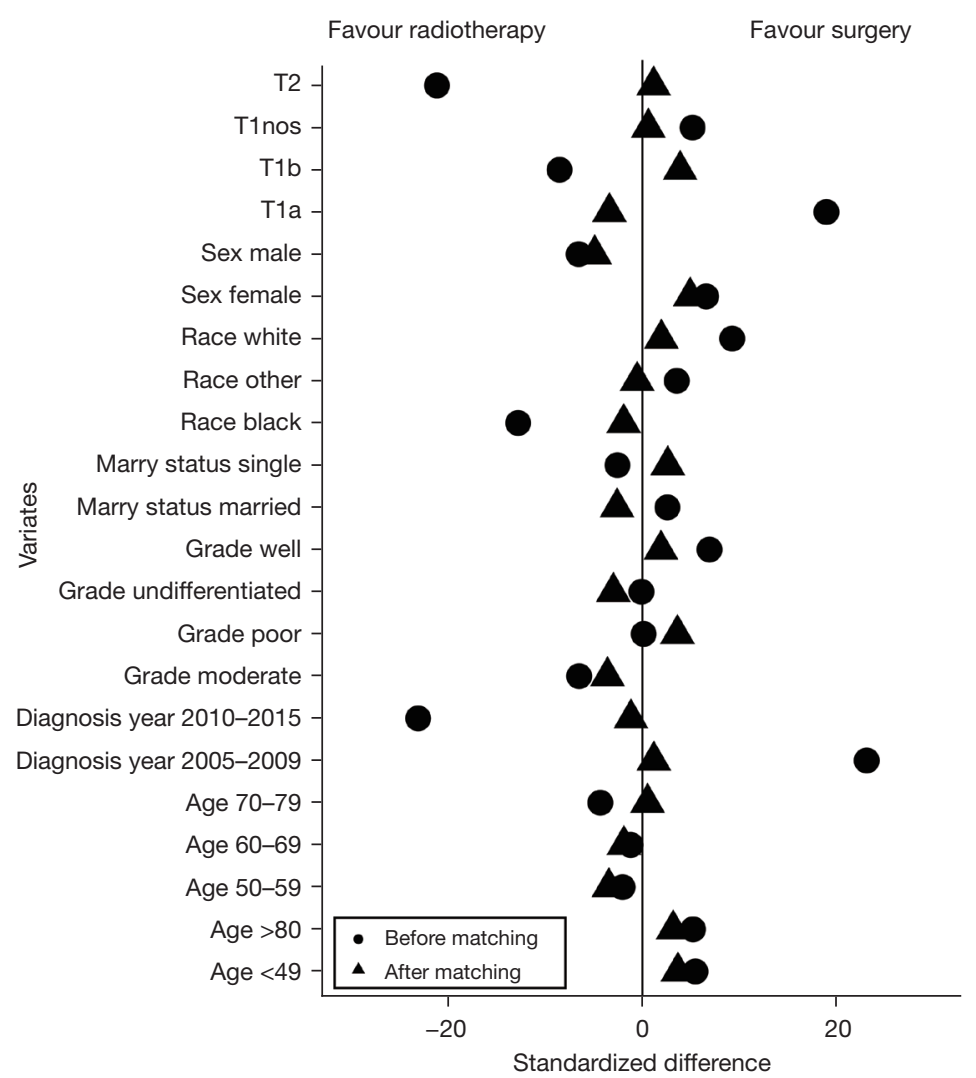

Figure 2 Comparison of standardized differences between patients undergoing surgery and receiving radiotherapy before and after propensity score matching. T1nos, T1 not specific.

In patients aged $\geq 70$ years, surgery was associated with significantly improved survival compared with radiotherapy (5-year CSS $84.5 \%$, 95\% CI: $80.6-88.4 \%$ vs. $77.4 \%$, 95\% CI: $72.3-82.4 \%$; P=0.009; Figure 4B). There was no significant difference in OS curves between the surgery and radiotherapy groups $(\mathrm{P}=0.12$; Figure $4 C)$. Competing risk analysis confirmed a tendency for a higher incidence of cancer-associated death among patients who received radiotherapy $(\mathrm{P}=0.01)$, with no significant difference in mortality due to other causes $(\mathrm{P}=0.33$; Figure $4 D)$.

We next performed univariate survival analysis (Table S4) and further multivariate survival analysis (Table 4) in patients aged $\geq 70$ years after PSM. Multivariate survival analysis revealed that, in patients aged $\geq 70$ years, age, $T$ stage, and treatment modality were independent prognostic factors for CSS. For patients aged $\geq 70$ years, the risk of death from cancer was significantly lower among patients undergoing surgery than among those receiving radiotherapy (aHR $=0.61,95 \%$ CI: $0.43-0.87 ; \mathrm{P}=0.006)$. However, treatment modality was not an independent predictor of OS in this subgroup of patients (aHR $=0.85,95 \%$ CI: $0.70-1.04$; $\mathrm{P}=0.118$ ). In patients aged $<70$ years, there were no significant differences in survival outcomes between the 2 treatment groups (Figure $4 A$ ). In addition, there were no significant differences in survival curves for the 2 treatment groups in the male/female, all $\mathrm{T}$ stage, or pathological grade subgroups (Figure S2).

\section{Discussion}

In the present study, we analyzed the survival of 3994 patients with early glottic SCC treated with surgery or radiotherapy. We found no clear evidence that a given treatment method was associated with improved survival in the overall cohort. However, surgery was associated with improved CSS in patients aged $\geq 70$ years.

The demographic and clinical characteristics of this cohort are similar to those in previous studies (11-13). The mean $( \pm \mathrm{SD})$ age of the present cohort was $65 \pm 11.4$ years, and the ratio of males to females was approximately 8.5:1. 


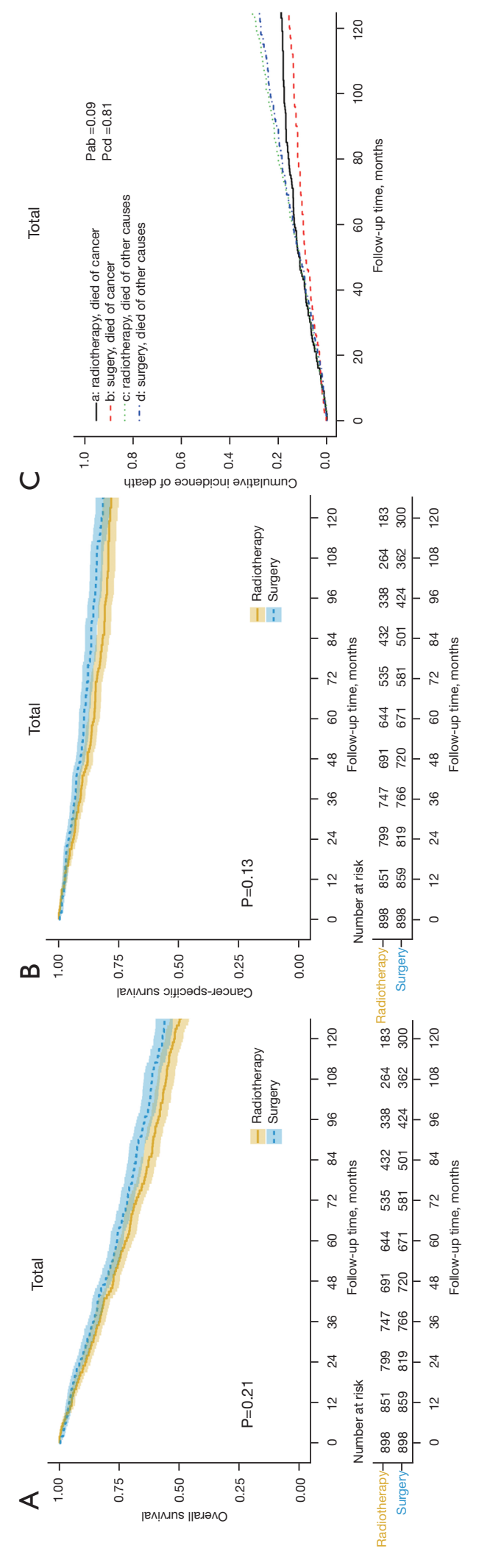

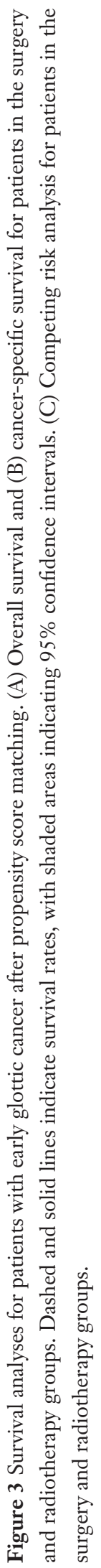

T1-stage disease accounted for $75 \%$ of the early stage glottic cancers, and most of the study cohort was White $(84.3 \%)$. Not only may patient-related variables affect treatment choice, but there is increasing evidence that these variables also affect survival outcomes in patients with cancer $(14,15)$. Chen et al. demonstrated that socioeconomic condition, insurance status, and race/ethnicity may affect treatment choice in patients with early stage laryngeal cancer (16). Another study of early-stage laryngeal cancer reported that patients treated with radiation therapy were more likely to be older and have a worse $\mathrm{T}$ stage (17). In the present study, patients treated with radiotherapy had a worse $\mathrm{T}$ stage, were more likely to be Black, and were more likely to have been recently diagnosed (2010-2015), suggesting a trend towards poor prognosis. Simple retrospective and population-based analyses may not be able to overcome these inherent biases in the different treatment arms. Consequently, PSM was used in the present study to balance the important patient-related characteristics. Our results indicate that the cofounding factors in the 2 treatment arms were well balanced after matching.

To date, only 1 randomized controlled trial has compared open surgery with radiotherapy in terms of the oncological outcomes of early glottic cancer (18). In that study, there was no significant difference in 5-year disease-free survival in the overall cohort, but the open surgery strategy showed a survival benefit in patients with T2 stage disease. However, the conclusions in that study are limited because of potential bias and the small sample size. Many retrospective studies, systemic reviews, and meta-analyses have investigated oncological outcomes following open surgery versus radiotherapy for early glottic cancer. Higgins et al. showed higher OS for transoral surgery compared with radiotherapy in a meta-analysis of 7,600 patients with early glottic cancer (19). In a meta-analysis of more than 1000 patients with early glottic cancer, Guimarães et al. found a trend favoring transoral laser surgery with improved CSS, OS, and larynx preservation compared with radiotherapy (20). Patients with T2 stage diseases often have a more unfavorable prognosis than do those with $\mathrm{T} 1$ stage diseases, regardless of treatment option. A meta-analysis from Warner et al. examined the local control rate in 1,159 patients with T2 stage glottic cancer and found no difference between radiotherapy and surgery (21). To summarize, most of the recent literature favors surgery, as it shows slightly better survival outcomes compared to radiotherapy. However, these analyses were inherently biased by patient selection. Similar to previous reports $(12,17)$, our analyses performed 
Table 3 Multivariate survival analysis for patients with early glottic cancer after propensity score matching

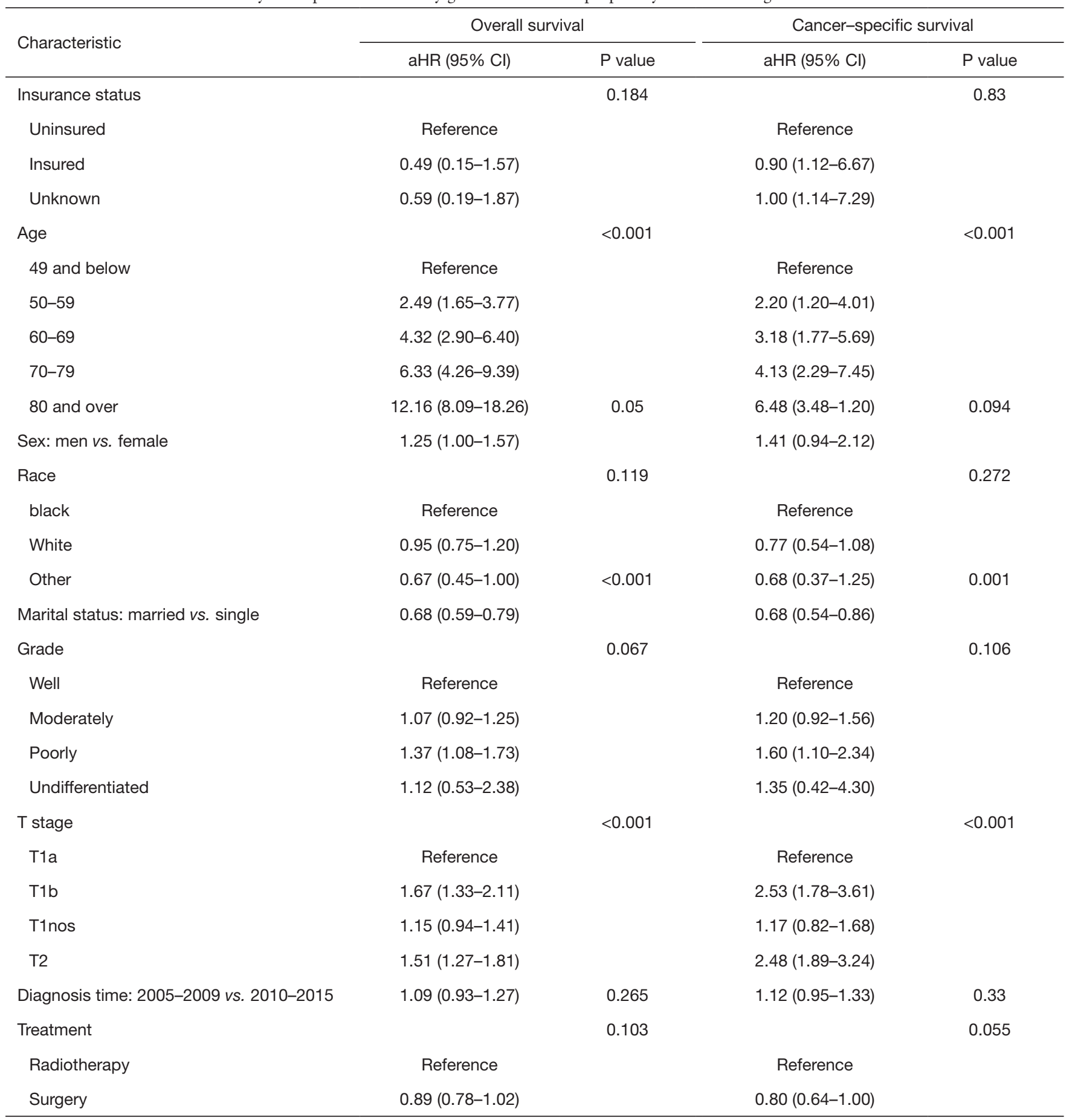

aHR, adjusted hazard ratio; T1nos, T1 not specific. 

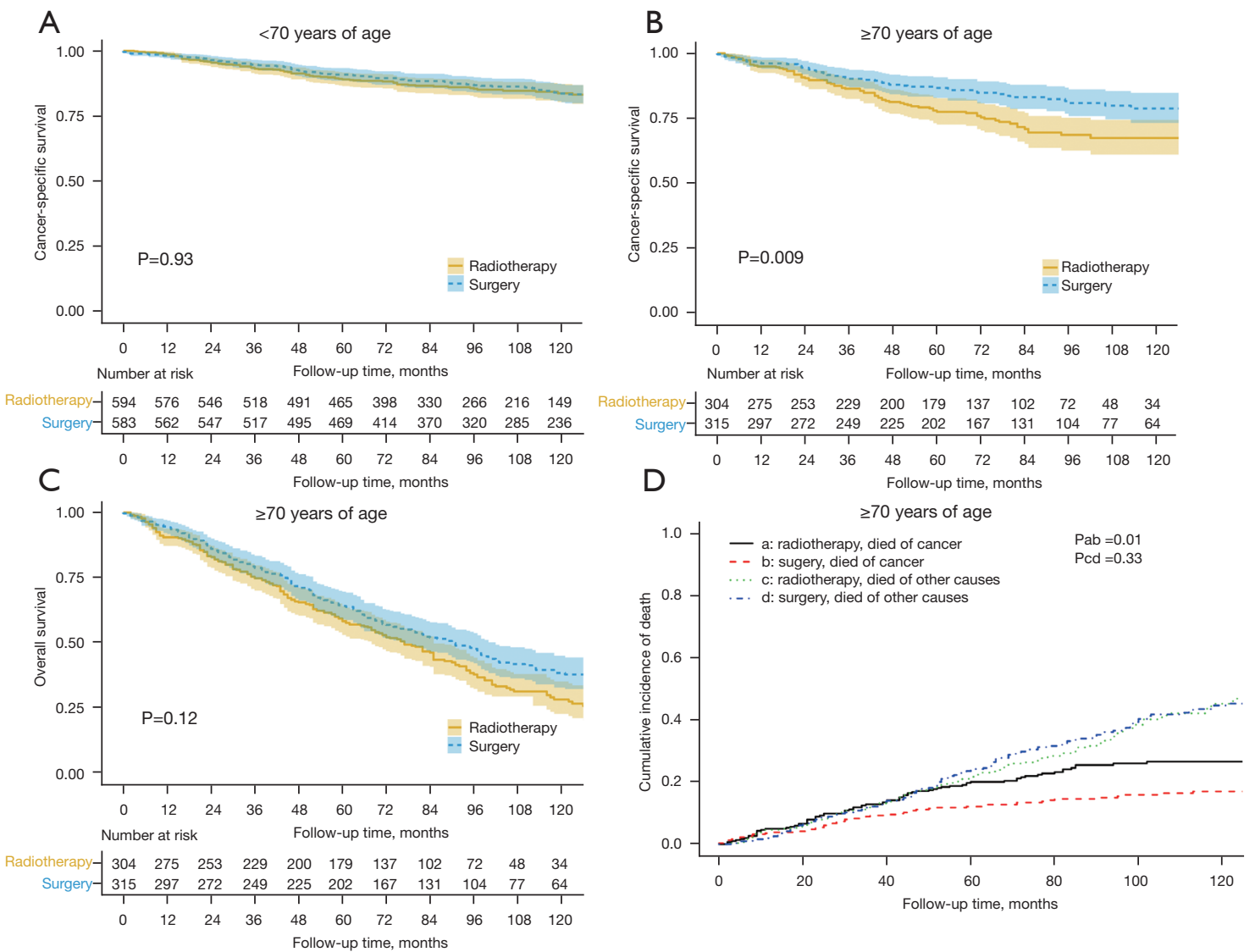

Figure 4 Survival analyses for patients with early glottic cancer stratified by age after propensity score matching. (A,B) Cancer-specific survival in patients aged $<70$ (A) and $\geq 70$ years (B). (C) Overall survival in patients aged $\geq 70$ years. Dashed and solid lines indicate survival rates, with shaded areas indicating $95 \%$ CIs. (D) Competing risk analysis for patients aged $\geq 70$ years.

without PSM indicated that patients treated with surgery had better OS and CSS outcomes than did patients treated with radiotherapy. Furthermore, this survival trend favoring surgery was also evident in the T1a, male, well/moderately differentiated grade, and all age subgroups. Surgery seems to improve the survival of patients with early glottic cancer better than radiotherapy based on our preliminary analyses. However, after PSM, there was no significant difference in OS and CSS between the surgery and radiotherapy groups for patients with early glottic cancer. Further subgroup analyses stratified by $\mathrm{T}$ stage, sex, and pathological grade also revealed comparable survival outcomes between the 2 treatment methods.

The management of older adult patients with laryngeal cancer is complex. Although approximately $25 \%$ of head and neck cancers occur in patients aged $\geq 65$ years (22), these patients are rarely enrolled in clinical trials. Older adult patients often have multiple comorbidities, poor performance status, and a relatively low tolerance to treatment, restricting their suitability for aggressive treatment approaches. A meta-analysis by Bourhis et al. investigated the outcomes of head and neck cancer patients treated with hyperfractionated and accelerated radiotherapy (23). In that study, older adult patients were less likely to benefit from radiotherapy than were younger patients in terms of OS, cancer-related survival, and local control rate. Another large retrospective cohort study reported decreased CSS in older adult compared with younger patients after radiotherapy treatment (24). In contrast, many studies have analyzed the survival of older adult patients after surgery and demonstrated no significant effect of age on treatment efficacy $(25,26)$. In the present study, cancer-related survival was significantly improved in older adult patients with early glottic cancer who underwent surgery compared with those who received radiotherapy. This superiority of surgery was not seen in 
Table 4 Multivariate survival analysis for patients aged 70 years and older after propensity score matching

\begin{tabular}{|c|c|c|c|c|}
\hline Characteristic & \multicolumn{2}{|c|}{ Overall survival } & \multicolumn{2}{|c|}{ Cancer-specific survival } \\
\hline Age (years) & & $<0.001$ & & 0.016 \\
\hline $70-80$ & Reference & & Reference & \\
\hline 80 and above & $1.90(1.55-2.33)$ & & 1.55 (1.08-2.23) & \\
\hline T1a & Reference & & Reference & \\
\hline $\mathrm{T} 1 \mathrm{~b}$ & $1.58(1.14-2.18)$ & & $2.32(1.37-3.92)$ & \\
\hline T1nos & $1.22(0.91-1.63)$ & & $1.50(0.90-2.49)$ & \\
\hline T2 & $1.26(0.95-1.67)$ & & $2.25(1.45-3.49)$ & \\
\hline Surgery & $0.85(0.70-1.04)$ & & $0.61(0.43-0.87)$ & \\
\hline
\end{tabular}

Only variables with $\mathrm{P}$ value $\leq 0.05$ were included in this table. aHR, adjusted hazard ratio; T1nos, T1 not specific.

younger patients. OS was similar between the 2 treatment methods in older adult patients. This may be due, in part, to most patients with laryngeal cancer dying from non-cancerrelated diseases, the incidences of which did not differ significantly between the 2 treatment arms, as shown by our competing risk analyses.

Notably, $66.7 \%$ and $54.5 \%$ of the deaths of patients with stage I and stage II diseases, respectively, were not related to laryngeal carcinoma (27). One study reported that radiation increased the occurrence of cerebrovascular disease in laryngeal cancers (28), whereas another study indicated that radiotherapy was related to an increased risk of developing secondary cancers overall, especially head and neck cancers and lung cancer (29). In the present study, there was no significant difference in mortality from other causes in patients who received radiotherapy compared with those who underwent surgery. The results were the same for older adult patients, who may have a poorer performance status, more comorbidities, and a poorer tolerance to treatment. Radiotherapy is relatively safe in early glottic carcinoma, and this may be related to the smaller field of radiotherapy. The radiotherapy field for other head and neck cancers or advanced laryngeal cancers includes the bilateral elective cervical lymph nodes $(30,31)$, whereas the radiotherapy field of early glottic cancer is limited to the laryngeal box (32). Currently, more advanced intensity-modulated radiation therapy technology allows for a reduced dose to other important structures, such as the carotid artery (33). Because of the lack of detailed information about radiotherapy in the SEER database, we cannot further analyze which radiotherapy pattern is safe and effective.

This study has several limitations. First, there was an inherent patient selection bias in retrospective studies. Patients in the surgery group had a better $\mathrm{T}$ stage, were more likely to be diagnosed between 2005 and 2009, and were less likely to be Black, which might have led to a better prognosis. Despite improvements in methods balancing the baseline covariates, bias could not be completely overcome considering that a number of variables significantly related to survival, such as comorbidities and performance status, were not available from the database. Second, detailed information, such as the radiotherapy regimen and whether the surgery performed was TLM or open surgery, was not provided in the database. Currently, TLM has largely replaced open surgery in early-stage laryngeal cancer due to its minimal invasiveness. Many studies have demonstrated similar OS and local control rates between the 2 methods for early laryngeal cancer $(34,35)$. However, open surgery may be better for lesions with deep infiltration (35). In the present study, both open surgery and TLM were categorized as part of the single "surgery" group. It would have been more meaningful if the analysis had been performed comparing just TLM and radiotherapy. In addition, T2b lesions have poorer local control rates 
and survival outcomes compared with general T2-stage diseases (21). The lack of detailed data regarding tumor characteristics and treatment regimens hampers our further research on this topic. Thus, high-quality randomized controlled trials are still needed to validate our results.

\section{Conclusions}

In conclusion, this study has demonstrated that, in patients with early glottic SCC, there is no sufficient evidence favoring surgery over radiotherapy in terms of survival. However, patients aged $\geq 70$ years might benefit from surgery with improved CSS. Yet, considering the inherent limitations of our retrospective study, randomized clinical trials with more rigorous criteria and specialized populations are still needed for a solid conclusion.

\section{Acknowledgments}

Funding: This work was supported by the National Natural Science Foundation of China (No. 82071034).

\section{Footnote}

Reporting Checklist: The authors have completed the STROBE reporting checklist. Available at https://atm. amegroups.com/article/view/10.21037/atm-21-5288/rc

Peer Review File: Available at https://atm.amegroups.com/ article/view/10.21037/atm-21-5288/prf

Conflicts of Interest: All authors have completed the ICMJE uniform disclosure form (available at https://atm. amegroups.com/article/view/10.21037/atm-21-5288/coif). The authors have no conflicts of interest to declare.

Ethical Statement: The authors are accountable for all aspects of the work in ensuring that questions related to the accuracy or integrity of any part of the work are appropriately investigated and resolved. The study was conducted in accordance with the Declaration of Helsinki (as revised in 2013).

Open Access Statement: This is an Open Access article distributed in accordance with the Creative Commons Attribution-NonCommercial-NoDerivs 4.0 International License (CC BY-NC-ND 4.0), which permits the noncommercial replication and distribution of the article with the strict proviso that no changes or edits are made and the original work is properly cited (including links to both the formal publication through the relevant DOI and the license). See: https://creativecommons.org/licenses/by-nc-nd/4.0/.

\section{References}

1. Chu EA, Kim YJ. Laryngeal cancer: diagnosis and preoperative work-up. Otolaryngol Clin North Am 2008;41:673-95, v.

2. SEER Cancer Stat Facts: Laryngeal Cancer. National Cancer Institute. Bethesda, MD, USA. [Accessed April 2021]. Available online: https://seer.cancer.gov/statfacts/ html/laryn.html

3. Ermiş E, Teo M, Dyker KE, et al. Definitive hypofractionated radiotherapy for early glottic carcinoma: experience of $55 \mathrm{~Gy}$ in 20 fractions. Radiat Oncol 2015;10:203.

4. Breda E, Catarino R, Monteiro E. Transoral laser microsurgery for laryngeal carcinoma: Survival analysis in a hospital-based population. Head Neck 2015;37:1181-6.

5. Baird BJ, Sung CK, Beadle BM, et al. Treatment of earlystage laryngeal cancer: A comparison of treatment options. Oral Oncol 2018;87:8-16.

6. Silver CE, Beitler JJ, Shaha AR, et al. Current trends in initial management of laryngeal cancer: the declining use of open surgery. Eur Arch Otorhinolaryngol 2009;266:1333-52.

7. Aaltonen LM, Rautiainen N, Sellman J, et al. Voice quality after treatment of early vocal cord cancer: a randomized trial comparing laser surgery with radiation therapy. Int J Radiat Oncol Biol Phys 2014;90:255-60.

8. Warner L, Chudasama J, Kelly CG, et al. Radiotherapy versus open surgery versus endolaryngeal surgery (with or without laser) for early laryngeal squamous cell cancer. Cochrane Database Syst Rev 2014;(12):CD002027.

9. Scrucca L, Santucci A, Aversa F. Competing risk analysis using R: an easy guide for clinicians. Bone Marrow Transplant 2007;40:381-7.

10. Cosetti M, Yu GP, Schantz SP. Five-year survival rates and time trends of laryngeal cancer in the US population. Arch Otolaryngol Head Neck Surg 2008;134:370-9.

11. Jones AS, Fish B, Fenton JE, et al. The treatment of early laryngeal cancers (T1-T2 N0): surgery or irradiation? Head Neck 2004;26:127-35.

12. Brady JS, Marchiano E, Kam D, et al. Survival Impact of Initial Therapy in Patients with T1-T2 Glottic Squamous Cell Carcinoma. Otolaryngol Head Neck Surg 2016;155:257-64. 
13. Remmelts AJ, Hoebers FJ, Klop WM, et al. Evaluation of lasersurgery and radiotherapy as treatment modalities in early stage laryngeal carcinoma: tumour outcome and quality of voice. Eur Arch Otorhinolaryngol 2013;270:2079-87.

14. Lebo NL, Khalil D, Balram A, et al. Influence of Socioeconomic Status on Stage at Presentation of Laryngeal Cancer in the United States. Otolaryngol Head Neck Surg 2019;161:800-6.

15. Chen JJ, Stessin A, Christos P, et al. Differences in survival outcome between stage I and stage II glottic cancer: A SEER-based analysis. Laryngoscope 2015;125:2093-8.

16. Chen AY, Fedewa S, Zhu J. Temporal trends in the treatment of early- and advanced-stage laryngeal cancer in the United States, 1985-2007. Arch Otolaryngol Head Neck Surg 2011;137:1017-24.

17. Zhan C, Yang X, Song X, et al. Radiotherapy vs surgery for T1-2N0M0 laryngeal squamous cell carcinoma: A population-based and propensity score matching study. Cancer Med 2018. [Epub ahead of print].

18. Ogol'tsova ES, Paches AI, Matiakin EG, et al. Comparative evaluation of the effectiveness of radiotherapy, surgery and combined treatment of stage I-II laryngeal cancer (T1$2 \mathrm{NoMo}$ ) based on the data of a cooperative randomized study. Vestn Otorinolaringol 1990;(3):3-7.

19. Higgins KM, Shah MD, Ogaick MJ, et al. Treatment of early-stage glottic cancer: meta-analysis comparison of laser excision versus radiotherapy. J Otolaryngol Head Neck Surg 2009;38:603-12.

20. Guimarães AV, Dedivitis RA, Matos LL, et al. Comparison between transoral laser surgery and radiotherapy in the treatment of early glottic cancer: A systematic review and meta-analysis. Sci Rep 2018;8:11900.

21. Warner L, Lee K, Homer JJ. Transoral laser microsurgery versus radiotherapy for $\mathrm{T} 2$ glottic squamous cell carcinoma: a systematic review of local control outcomes. Clin Otolaryngol 2017;42:629-36.

22. Muir CS, Fraumeni JF Jr, Doll R. The interpretation of time trends. Cancer Surv 1994;19-20:5-21.

23. Bourhis J, Overgaard J, Audry H, et al. Hyperfractionated or accelerated radiotherapy in head and neck cancer: a meta-analysis. Lancet 2006;368:843-54.

24. Huang SH, O'Sullivan B, Waldron J, et al. Patterns of care in elderly head-and-neck cancer radiation oncology patients: a single-center cohort study. Int J Radiat Oncol Biol Phys 2011;79:46-51.
25. Kowalski LP, Alcantara PS, Magrin J, et al. A case-control study on complications and survival in elderly patients undergoing major head and neck surgery. Am J Surg 1994;168:485-90.

26. Morgan RF, Hirata RM, Jaques DA, et al. Head and neck surgery in the aged. Am J Surg 1982;144:449-51.

27. Ferlito A, Haigentz M Jr, Bradley PJ, et al. Causes of death of patients with laryngeal cancer. Eur Arch Otorhinolaryngol 2014;271:425-34.

28. Swisher-McClure S, Mitra N, Lin A, et al. Risk of fatal cerebrovascular accidents after external beam radiation therapy for early-stage glottic laryngeal cancer. Head Neck 2014;36:611-6.

29. Gao X, Fisher SG, Mohideen N, et al. Second primary cancers in patients with laryngeal cancer: a populationbased study. Int J Radiat Oncol Biol Phys 2003;56:427-35.

30. Forastiere AA, Goepfert H, Maor M, et al. Concurrent chemotherapy and radiotherapy for organ preservation in advanced laryngeal cancer. N Engl J Med 2003;349:2091-8.

31. Tao Y, Auperin A, Blanchard P, et al. Concurrent cisplatin and dose escalation with intensity-modulated radiotherapy (IMRT) versus conventional radiotherapy for locally advanced head and neck squamous cell carcinomas (HNSCC): GORTEC 2004-01 randomized phase III trial. Radiother Oncol 2020;150:18-25.

32. Gujral DM, Long M, Roe JW, et al. Standardisation of Target Volume Delineation for Carotid-sparing Intensitymodulated Radiotherapy in Early Glottis Cancer. Clin Oncol (R Coll Radiol) 2017;29:42-50.

33. Berwouts D, Swimberghe M, Duprez F, et al. Intensitymodulated radiotherapy for early-stage glottic cancer. Head Neck 2016;38 Suppl 1:E179-84.

34. Jacobi C, Freundorfer R, Reiter M. Transoral laser microsurgery in early glottic cancer involving the anterior commissure. Eur Arch Otorhinolaryngol 2019;276:837-45.

35. Luo C, Lv K, Liu Q, et al. Comparison of laser microsurgery and open partial laryngectomy for T1-2 laryngeal cancer treatment. Ann Transl Med 2021;9:464.

Cite this article as: Wang WL, Zheng HW, Zhang LH, Yu LS. Effect of treatment modality on the long-term survival of patients with early glottic squamous cancer: a retrospective cohort study based on the SEER database. Ann Transl Med 2022;10(8):440. doi: 10.21037/atm-21-5288 


\section{Supplementary}

A

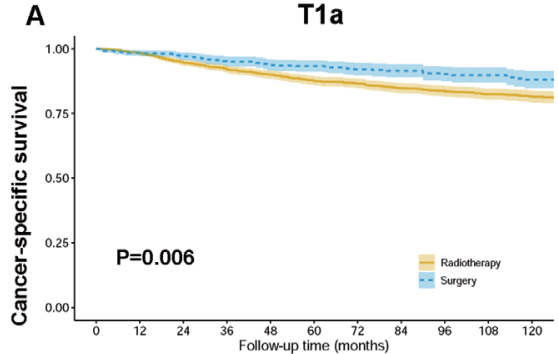

Number at risk

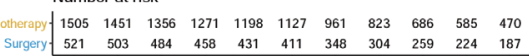

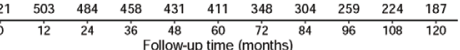

D

$<70$ years of age

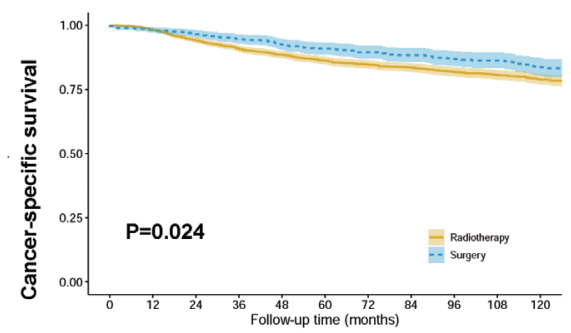

Number at risk

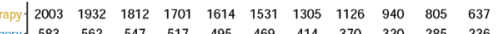

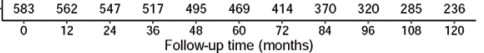

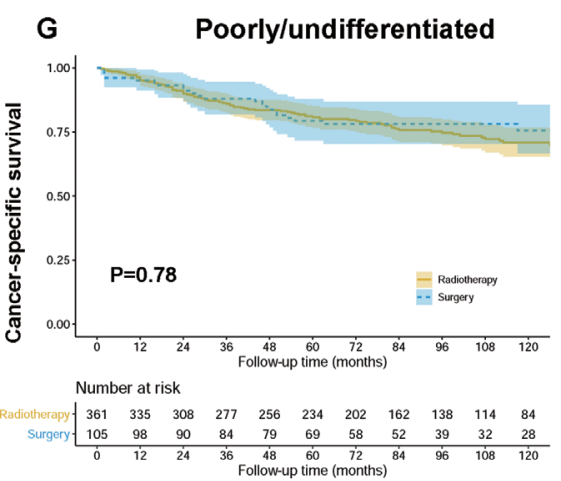

B

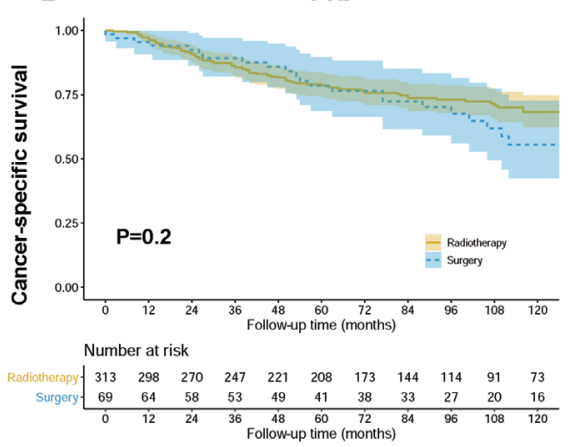

E
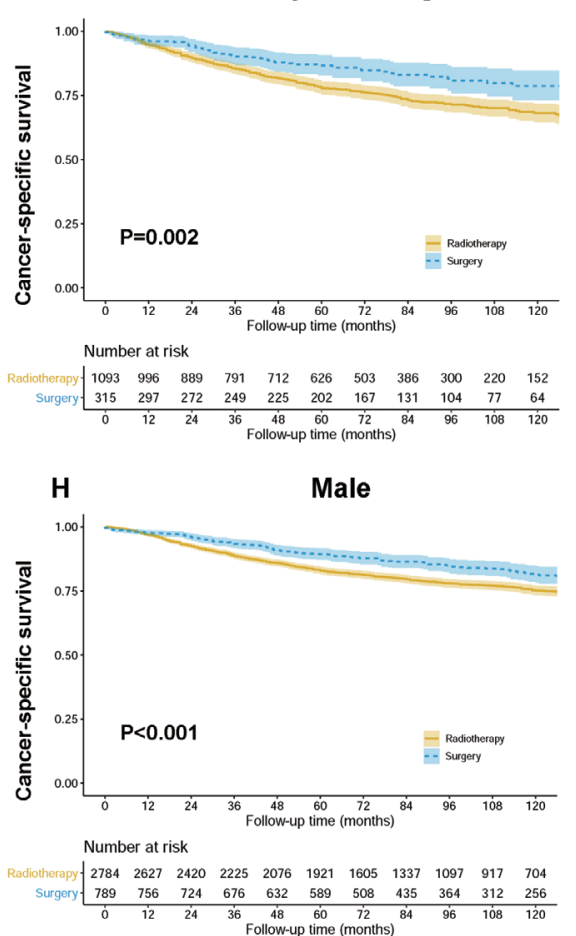

C

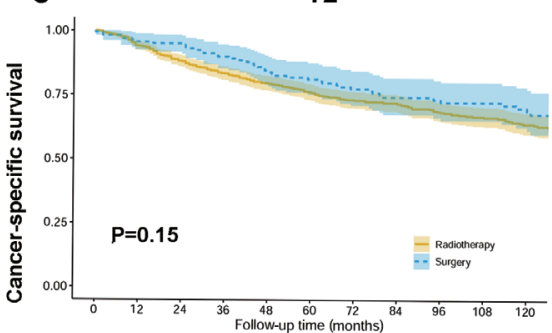
Number at risk

py \begin{tabular}{|lllllllllll}
842 & 759 & 679 & 608 & 562 & 511 & 412 & 343 & 273 & 215 & 160
\end{tabular}

\begin{tabular}{ccccccccccc}
165 & 154 & 150 & 138 & 127 & 113 & 100 & 88 & 76 & 69 & 59 \\
\hline 0 & 12 & 24 & 36 & 48 & 60 & 72 & 84 & 96 & 108 & 120 \\
& & \multicolumn{8}{c}{ Follow-up time (months) }
\end{tabular}

F Welll/moderately differentiated

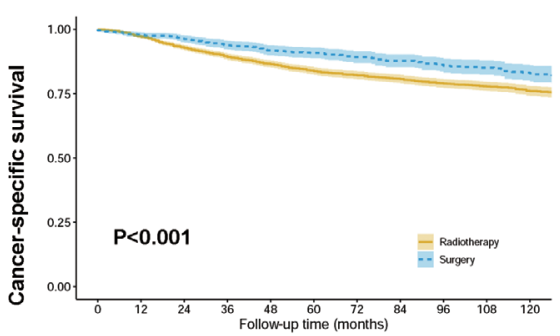

Number at risk

apy \begin{tabular}{|lllllllllll}
2735 & 2593 & 2393 & 2215 & 2070 & 1923 & 1606 & 1350 & 1102 & 911 & 705
\end{tabular}

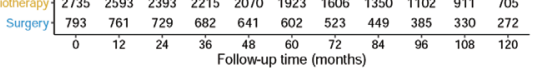

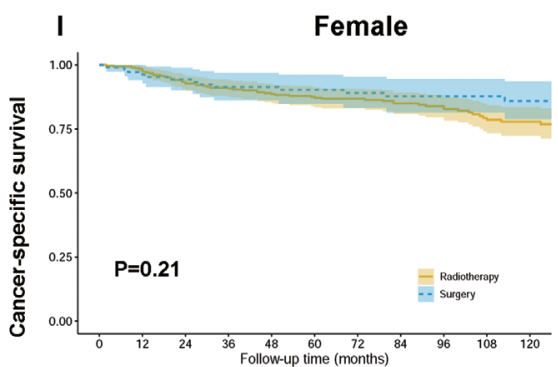

Number at risk

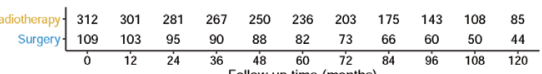

Figure S1 Subgroup analyses of cancer-specific survival for patients with early glottic cancer before propensity score matching according to (A-C) T stage, (D,E) age, (F,G) pathological grade, and (H,I) sex. Dashed and solid lines indicate survival rates, with shaded areas indicating $95 \%$ CIs. 
A

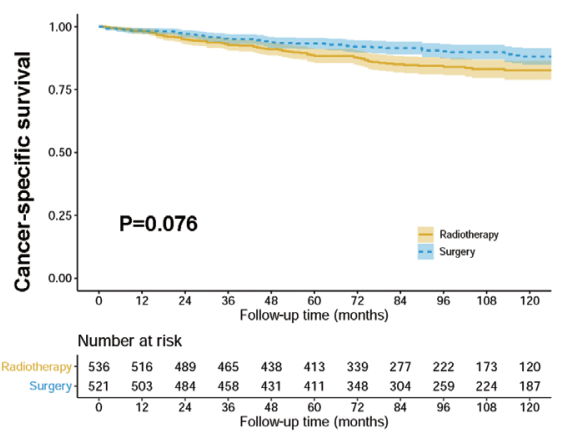

D Welll/moderately differentiated
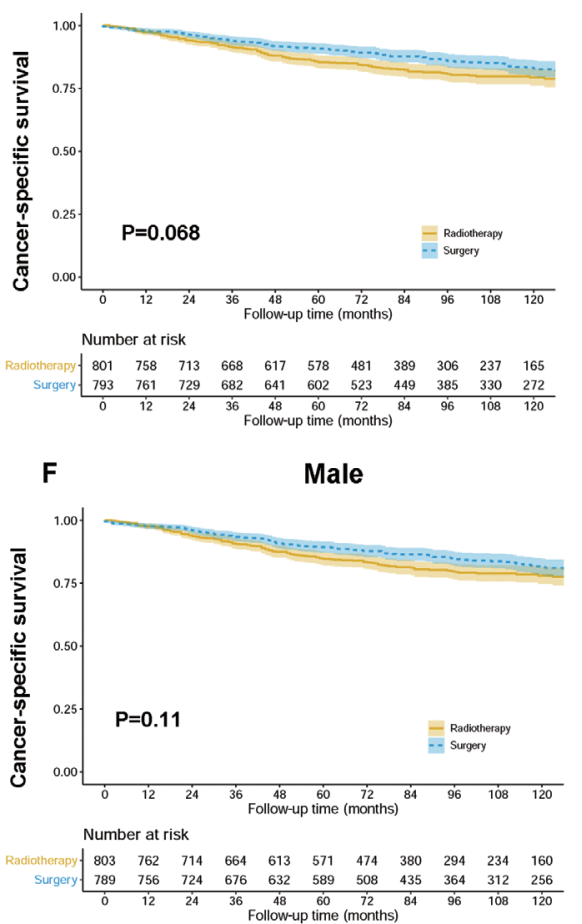

B

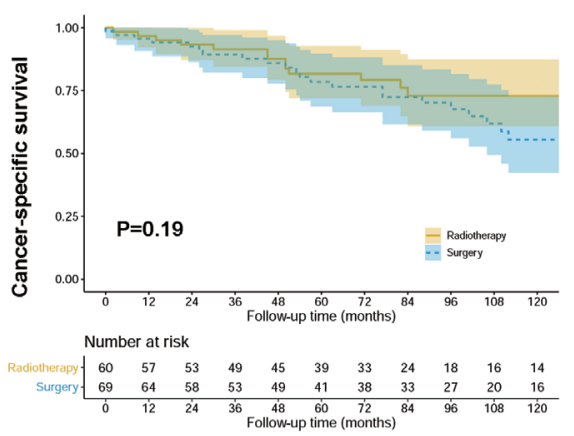

$E$
C

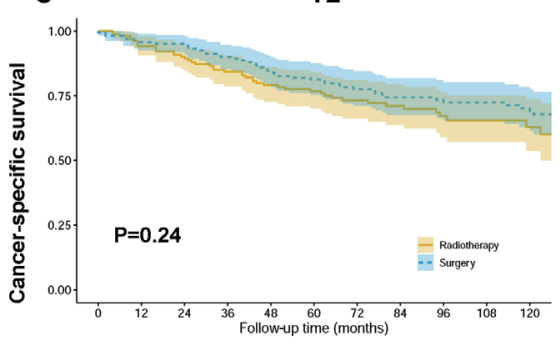

Number at risk

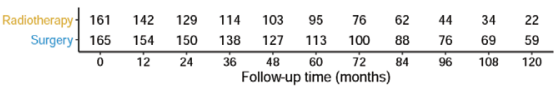

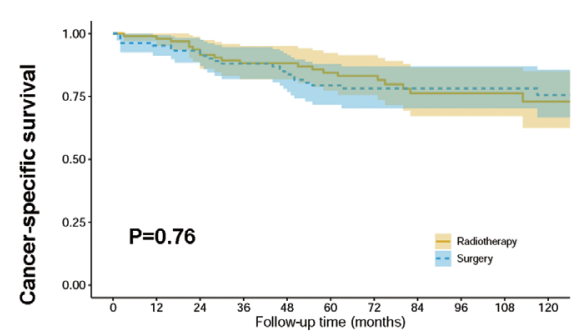

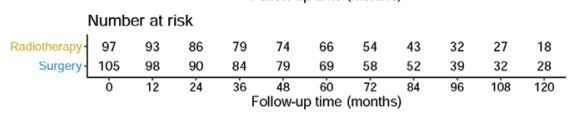

G

Female
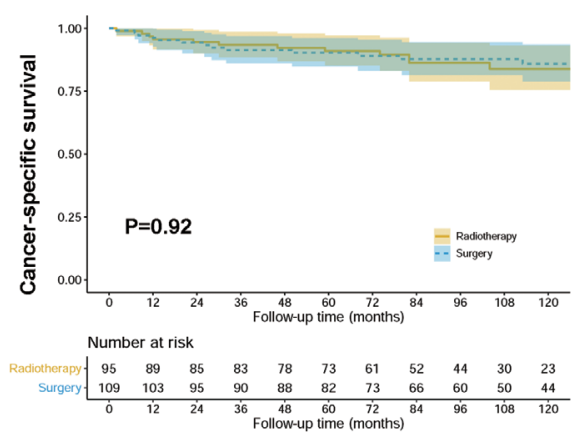

Figure S2 Survival analyses for patients with early glottic cancer stratified by (A-C) T stage, (D,E) pathological grade, and (F,G) sex after propensity score matching. Dashed and solid lines indicate survival rates, with shaded areas indicating $95 \%$ CIs. 
Table S1 Univariate survival analysis for patients with early glottic cancer before propensity scores matching

\begin{tabular}{|c|c|c|c|c|}
\hline Characteristic & \multicolumn{2}{|c|}{ Overall survival } & \multicolumn{2}{|c|}{ Cancer-specific survival } \\
\hline Insurance status & & 0.67 & & 0.61 \\
\hline Uninsured & Reference & & Reference & \\
\hline Insured & $0.96(0.45-2.05)$ & 0.926 & $0.64(0.26-1.57)$ & 0.335 \\
\hline Age & & $<0.001$ & & $<0.001$ \\
\hline 49 and below & Reference & & Reference & \\
\hline $50-59$ & $1.70(1.33-2.18)$ & $<0.001$ & $1.46(1.05-2.05)$ & 0.023 \\
\hline $60-69$ & $2.91(2.31-3.67)$ & $<0.001$ & $2.13(1.56-2.91)$ & $<0.001$ \\
\hline Sex: men vs. female & $1.20(1.03-1.39)$ & 0.017 & $1.25(0.98-1.59)$ & 0.06 \\
\hline Race & & 0.079 & & 0.005 \\
\hline Black & Reference & & Reference & \\
\hline White & $0.94(0.82-1.07)$ & 0.359 & $0.71(0.59-0.87)$ & 0.001 \\
\hline Other & $0.74(0.56-0.97)$ & 0.029 & $0.73(0.49-1.07)$ & 0.106 \\
\hline Marital status: married vs. single & $0.71(0.65-0.78)$ & $<0.001$ & $0.69(0.60-0.79)$ & $<0.001$ \\
\hline Pathological grade & & 0.005 & & 0.004 \\
\hline Well & Reference & & Reference & \\
\hline $\mathrm{T} 1 \mathrm{~b}$ & $1.53(1.32-1.76)$ & $<0.001$ & $2.23(1.79-2.76)$ & $<0.001$ \\
\hline T1nos & $1.02(0.88-1.78)$ & 0.786 & $1.08(0.85-1.37)$ & 0.534 \\
\hline $\mathrm{T} 2$ & $1.50(1.35-1.67)$ & $<0.001$ & $2.33(1.98-2.73)$ & $<0.001$ \\
\hline Diagnosis time: $2005-2009$ vs. $2010-2015$ & $1.03(0.93-1.14)$ & 0.56 & $1.17(0.99-1.37)$ & 0.06 \\
\hline Treatment & & 0.001 & & $<0.001$ \\
\hline Radiotherapy & Reference & & Reference & \\
\hline Surgery & $0.84(0.75-0.93)$ & 0.001 & $0.72(0.60-0.86)$ & $<0.001$ \\
\hline
\end{tabular}

AHR, adjusted hazard ratio. 
Table S2 Multivariate survival analysis for patients with early glottic cancer before propensity scores matching

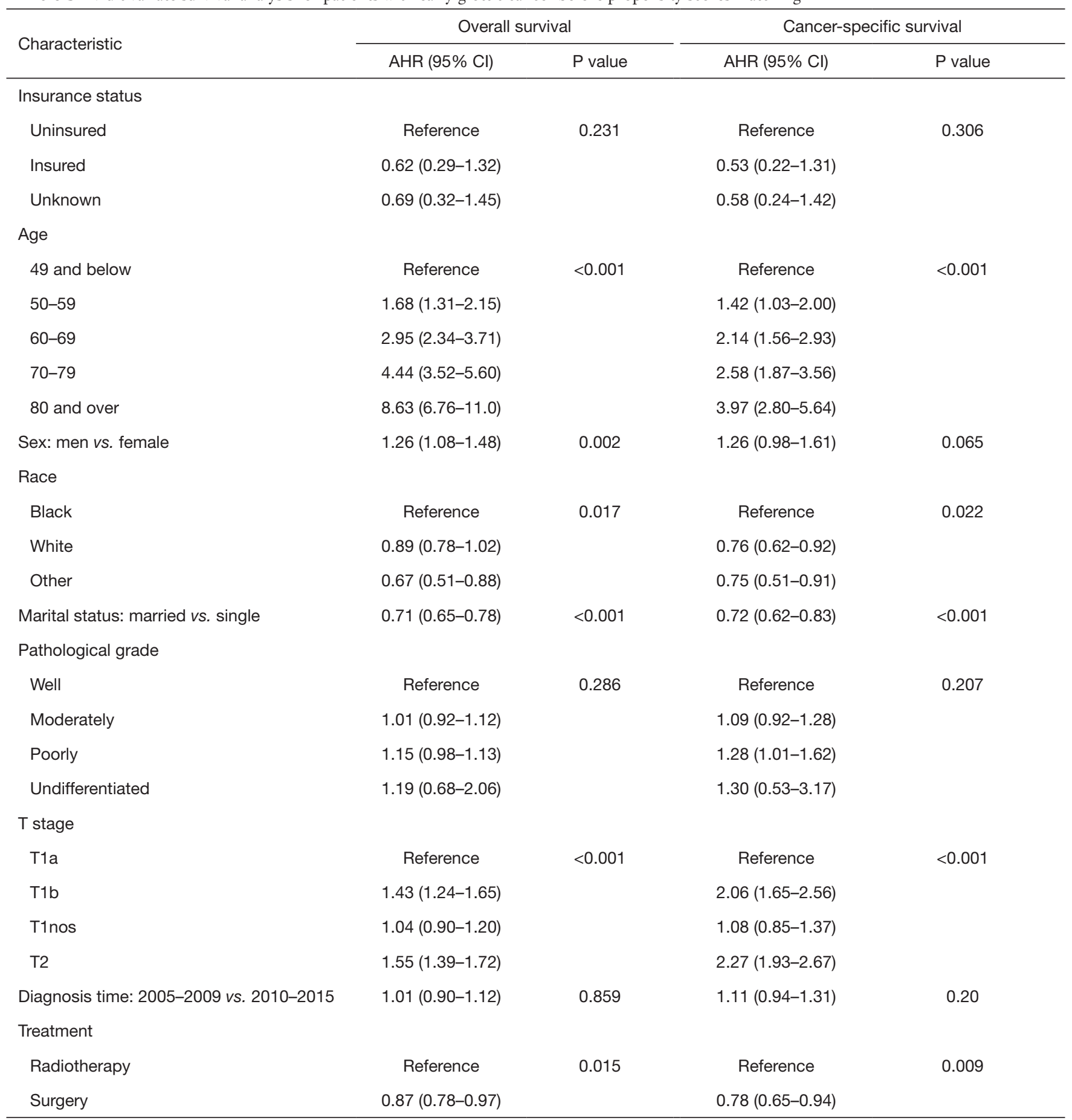

AHR, adjusted hazard ratio. 
Table S3 Univariate survival analysis for patients with early glottic cancer after propensity scores matching

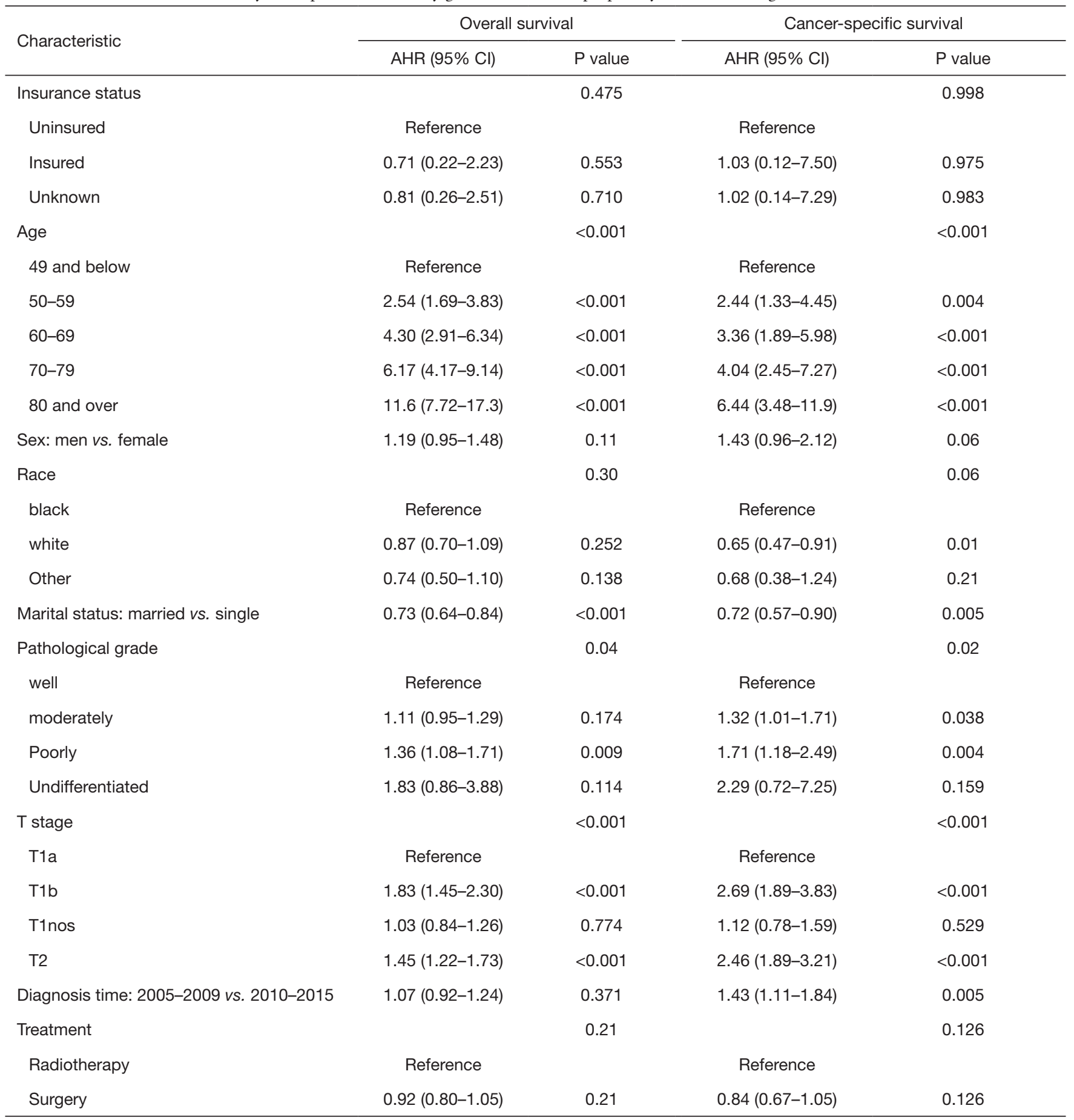

AHR, adjusted hazard ratio. 
Table S4 Univariate survival analysis for patients aged 70 years and older with early glottic cancer after propensity scores matching

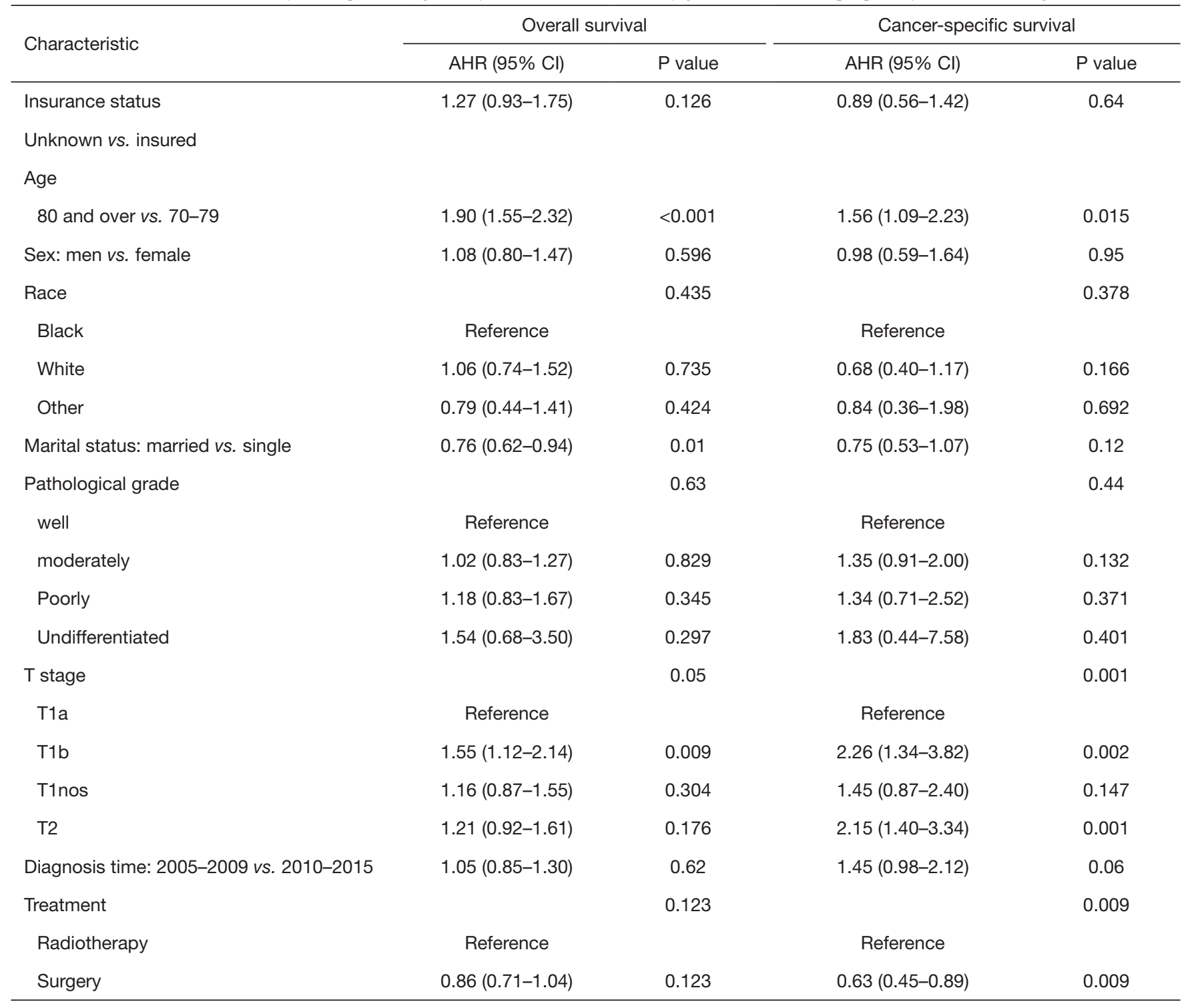

AHR, adjusted hazard ratio. 